the Isle of Wight, where earth-tremors appear to be of constant occurrence, and stated that he had been able to feel certain tremors at a distance of several thousands of miles. Indeed, he went further and, calculating that one shock had reached his instruments from a distance of not less than 6,000 miles, he stated the extreme probability that a shock had occurred in Japan on August 31st, a prediction which was verified at the close of the meeting.

The Coral Reef Committee had to announce that so far as the boring at Funafuti went it was practically a failure, but that the results brought back by the scientific officers of the ship and by the three naturalists engaged in the investigation, were of very great importance from the points of view of anthropology, zoology, botany, geology and hydrography. The Geological Photographs Committee reported that a large part of Britain was now photographically registered in the collection of 1,400 prints which had been amassed, but there were many areas ill-represented and others almost as yet untouched. In conclusion, a discovery by Prof. Busz must not be omitted. Amongst some remarkable rocks produced by contact metamorphism round the Dartmoor granite mass he had found and isolated corundum in a felsite which had enclosed and metamorphosed a fragment of slate.

LONDON.

W. W. WATtS.

\section{RELATIONS OF TARSIUS TO THE LEMURS AND APES.}

THE systematic position of the Lemuroidea has for years puzzled the most eminent naturalists. The French zoologists, including Alphonse Milne-Edwards, Gervais and Filhol,consider the Lemurs as occupying a position entirely apart from the Apes, and moreover some of these observers find in the anatomy of the soft parts of the Lemurs close resemblances structurally to the same parts in the Ungulates. The conclusions of Filhol in regard to the position of the fossil Lemurs have not been generally accepted by paleontologists, and there is no doubt that certain characters of the dentition of Adapis which are like those of the perissodactyle Ungulates must be considered as cases of parallelism.

Years ago Mivart ably contended for the close affinity between the Apes and Lemurs, and Cope saw in Anaptomorphus the most simian lemur yet discovered. Schlosser, on paleontological grounds, derives the Anthropoids and Lemuroids from the same stem form.

Up to the present time the genus Tarsius has been considered to be a member of the Lemuroidea, but the recent investigations of Hubrecht on the placentation of Tarsius go to show that this genus has the same type of placenta as in the Apes. Accordingly Hubrecht would transfer Tarsius from the Lemuroid to the Anthropoid division of the Primates. In this removal of Tarsius to the Anthropoids, he proposes to include Anaptomorphus, and if the latter genus is placed among the Apes, why not place Necrolemur there too, as it has probably the same dental formula as Tarsius, and the modification of the anterior part of the dentition in Necrolemur resembles that of Tarsius.

It appears to me if this change in the classification of the Primates takes place we shall be little benefited and that it will be exceedingly difficult to discover any characters of the skeleton by which we can separate the Apes from the Lemurs. I hold that the summation of the osteological characters of Tarsius brings this form nearer the Lemurs than the A pes, and, moreover, I know of only one Anthropoid character in the skeleton of Tarsius; this is the partial closure inferiorly of the orbital fossa, by a lamina of bone extending from the alisphe- 
noid to the malar. I admit this character occurs in no other known Lemuroid. However, in the fossil genera related to Tarsius, that is in Anaptomorphus and Necrolemur, this sphenoidal lamina in the skull is not present.

In support of the view that Tarsius is a generalized member of the Lemuroidea, I wish to enumerate a number of its most important dental and osteological characters: the lower incisors and canines are normal in form as in the extinct ancestral Lemurs, the lachrymal fossa is exposed as in the Lemurs, the fourth digit of the pes is longer than the third, the second digit of the pes is provided with a claw, and, lastly, the calcaneum and navicular are elongated as in Galago and Cheirogaleus. These characters are all those of the true Lemurs, and I believe they are essential. In regard to the presence of a claw on the second digit of the pes, that may be considered a primitive character, as in my opinion the Lemurs have been derived from an unguiculate form, and not from an ungulate type (Condylarthra).

I do not see that the characters of the dentition of Tarsius bear directly on the question as to its close relationship with the Apes. The upper molars of Tarsius are of the primitive tritubercular type, and the lower are tuberculo-sectorial. These types of teeth would be the primitive ones from which those of both the Apes and Lemurs were derived.

The form of the incisors and canines in Anaptomorphus is not known, but from the resemblance of the skull of Anaptomorphus to that of Necrolemur and Tarsius one might conclude that the anterior part of the dentition would be like that of Tarsius. In Anaptomorphus homunculus, as shown by Osborn and Wortman, there are three lower premolars, but in $A$. aemulus there are said to be only two. In other words, the lastnamed species is supposed to have the true simian dental formula, namely: $\mathrm{I}_{2}, \mathrm{C}_{1}, \mathrm{Pm}_{2}$, $M_{3}$. I believe, however, that we may interpret the arrangement of the teeth in "Anaptomorphus aemulus differently, and in that case the lower dental formula would read: $\mathrm{I}_{1}, \mathrm{C}_{1}, \mathrm{Pm}_{3}, \mathrm{M}_{3}$, or the same as in Tarsius.

The structure of the skull in Necrolemur, Anaptomorphus and Tarsius is very similar. In all we have greatly enlarged orbits and huge auditory bullæ. In comparing the teeth of these genera, we find that Anaptomorphus and Tarsius have retained the primitive tritubercular structure in their true molars, whereas in Necrolemur the superior molars are of the quadritubercular type, and the lower true molars have lost the antero-internal cusp. One character of the dentition of Anaptomorphus, as shown by Cope, relates this genus more closely to the Anthropoids than any other known Lemur; this is, that the third upper premolar has an internal cusp as in the Apes. With the exception of this special dental character, Anaptomorphus is a true Lemur.

In Adapis of the Upper Eocene of Europe the general structure of the Molars closely resembles that of the recent Lemurs, especially the genera Lemur and Lepidolemur. In Adapis however, the pattern of the last lower and upper premolar is nearly like that of the true molars; and on account of the complex structure of this tooth, Adapis has been excluded from the line leading to any of the recent Lemurs. This objection as to the Adapidce being ancestral forms can now be removed, as there is a beautifully preserved skull in the collection of the Jardin des Plantes, Paris, from the Phos. phorites, which represents a new genus of this family, and the last premolar in both jaws of this new type is perfectly simple in structure and of the same form as in the majority of recent Lemurs. This cranium is essentially that of a living Lemur, closely allied to 
Hapalemur, but with one important exception, namely, the incisors and canines, are normal in form, and not proclivous, as in recent Lemurs. This is exactly what we should expect to find in an ancestral Lemur, as that peculiar modernization in the form of the lower incisors and canines in the Lemurs probably occurred at a very late geological epoch. In the jaw of Megaladapis, of the late Tertiary or Pleistocene epoch of Madagascar, the incisors are not preserved, but, from the extreme massiveness of the jaw symphysis and its upward bend, I think further discovery will show that in this form the lower anterior teeth were upright in position as in the Eocene Lemurs.

As already mentioned, the teeth of the Old World Adapidae closely resemble those of the recent Lemuroidea, especially the forms included in the subfamily Lemurince. The American forms which are supposed to be related to Adapis cannot be considered as ancestral to any of the existing Lemurs, on account of the sexitubercular structure of their superior molars. The question is: Are these American genera monkeys? As before stated, it is very probable that the ancestral Lemur had a generalized type of dentition in that the incisors and canines were of the normal form, as in the Apes. The Hyopsodontides then can hardly be designated as monkeys, simply because they have retained, in the shape of their anterior teeth, the form common to to the ancestors of both monkeys and Lemurs. The term Pseudolemurs, which Schlosser has proposed to apply to fossil Lemurs, with the full number of premolars, is appropriate especially for the American fossil lemurines. Moreover, this name has the advantage of showing that these forms are not directly ancestral to the true Lemurs, but that they developed parallel with the latter.

Mivart, in discussing the relations of the Lemurs to the Ungulates, came to the con- clusion, that merely on account of the similar structure of the placenta in these two groups, as a result, they cannot be considered as closely related. For we know that in the order Edentata there are several well marked types of placentæ, as the zonary of Orycteropus, (2) the diffuse Manis and the discoidal deciduate of the Armadillos and Sloths. Again, as Balfour remarks, "The presence of zonary placentæ in Hyrax and Elephas does not necessarily afford any proof of affinity of these types with the Carnivora." He further states that the resemblance between the metadiscoidal placenta of man and of the Cheiroptera, Insectivora and $R_{0-}$ dentia is rather physiological than morphological. Balfour considers that, although the placenta is capable of being used to some extent in classification, it does not warrant its being employed except in conjunction with other characters.

In conclusion, from a study of the osteology of the recent and extinct Lemuroidea, I believe that this suborder of the Primates is related genetically to the Apes, that Tarsius is a true synthetic type, connecting the Lemuroids with the Anthropoids, finally Tarsius shows that both Apes and Lemurs have arisen from a common ancestral form.

Charles Earle.

american Museum of Natural History.

THE PRIMARY SEGMENTATIONOF THE BRAIN.

IN a recent paper on the 'Segmentation of the Nervous System of Squalus acanthias,' Dr. H. V. Neal of Harvard University, entirely sets aside the 'Metameres,' or 'Neural Segments' observed by Locy in the neural folds, as not having any phylogenetic significance whatever. This conclusion is particularly interesting when it is taken into account that Locy claims to have traced these "Neural Segments onward in an unbroken continuity until they become the "neuromeres' of other observers."

In addition to the above, the chief con- 